\title{
PRODUCT QUALITY IMPROVED USING TRIZ: A CASE STUDY IN INCREASING INNOVATIVE OPTIONS IN MANUFACTURING SECTOR APPLICATION OF TRIZ TO REDUCE OF PARTICULATE MATTER IN CLEANED ENGINE BLOCKS
}

\author{
Sunil N. Adhikary ${ }^{1}$, Rajesh B. Buktar ${ }^{2}$ \\ ${ }^{I}$ Post Graduation Student, Department of Mechanical Engineering, Sardar Patel College of Engineering, Maharashtra, \\ India \\ ${ }^{2}$ Head of the department, Department of Mechanical Engineering, Sardar Patel College of Engineering, Maharashtra, \\ India
}

\begin{abstract}
The enormous potential of process innovation and optimization is often undervalued. In order to stay competitive organizations are forced to adapt quality of products and production to permanently growing requirements. Modern manufacturing processes need to fulfill highest demands on quality, efficiency, flexibility and reliability. The increasing complexity and integration of production systems and rate of demand complicate their optimization and somewhere thus quality gets hampered. Hence, the classical approaches of quality problem solving reach their limits. Depending on the development state of the production system, exponential improvement can only be achieved, using a modern potent tool that considers and questions the existing system structure as a whole and enables innovative process design. However, up to now operational practice mostly focuses on the improvement of single process steps (isolation) and improves quality in small increment only within the existing structures. Thus, a large potential for quality breakthrough crusade stays unutilized in the manufacturing area.

In a process chain the project team has to face a problem which is usually characterized by many requirements and objectives, some of which are conflicting. The team may have to solve a problem with no known solution. This is called an inventive problem and may contain contradictory requirements. Knowledge and creativity are two essential conditions for a successful solution. TRIZ mainly hovers around this concept [Ref 3], This paper describes a case study involving the application of TRIZ to achieve breakthrough quality result in automotive industry where such contradictory requirement existed. The work described in the paper builds on a recent substantial foundational support for innovation rendered by the Author's ${ }^{1}$ work organization and his project guide ${ }^{2}$. In this paper, the Author's ${ }^{1}$ version and his learning curve for TRIZ has been described and how the authors used TRIZ to solve a chronic quality and safety issue that wasn't getting solved by traditional approaches of problem solving methodologies. In this paper, an attempt is made by the authors to acquaint readers with the origination of TRIZ, its history, several tools of tools, how TRIZ is advancing with test of time and is still mystical and a young concept for thinking engineers.
\end{abstract}

Keywords: Atshuller, Abstraction, Psychological inertia, Technical and physical contradiction, Su-field diagram

\section{INTRODUCTION TO "TRIZ" [TEORIYA}

\section{RESHENIYA IZOBRETATELSKIKH ZADATCH]}

TRIZ is the acronym for "Theory of Inventive Problem Solving," in Russian pronounced as. TRIZ was developed by Genrich Altshuller and his coworkers during their stay in political asylum in the former USSR circa 1946, and is now being practiced throughout the world and the methodology is digitized in order to create smart TRIZ softwares.

TRIZ research began with the hypothesis that there are universal principles of invention that are the basis for creative innovations that advance technology, and that if these principles could be identified and codified, they could be taught to people to make the process of invention more predictable. The research has proceeded in several stages over the last 50 years. Over 2 million patents have been examined, classified by level of inventiveness, and analyzed to look for principles of innovation. The three primary findings of their research are as follows:

1. Problems and solutions were repeated across industries and sciences 
2. Patterns of technical evolution were repeated across industries and sciences

3. Innovations used scientific effects outside the field where they were developed i.e. mechanical branch problem solved using electrical engineering solution

Apparently, TRIZ consists of learning these repeating patterns of problems-solutions and patterns of technical evolution, and methods of using scientific effects, and applying them in order to get desired result without harming the health of the system.

\section{HOW TRIZ WORKS?}

During his political asylum, Altshuller and his coworkers initially tried to understand invention by empirically studying patents. He studied 200000 patents and derived a common analogy that there are five levels of invention. They are as Level 1- Standard Solutions, Level 2- Improvement, Level 3Invention inside paradigm, Level 4- Invention outside paradigm, Level 5- Discovery (Real Eureka!)

In accordance to the above study [Ref 1], Altshuller also found regularities in engineered technological systems that are primarily governed by eight laws of development. They are as follows viz. law of completeness of parts of a system, law of energy conductivity of system, law of harmonization of rhythms, law of increasing ideality, law of uneven development of parts, law of transition of system to supersystem, law of transition from macro level to micro level, law of increasing substance field involvement. Later one more law of dynamism was devised by his followers.

Altshuller was having strong belief that for bringing any change one needs to overcome his psychological inertia and challenge the current system (thou shalt, law of land thinking). He meant that one must take a system towards ideality (halo effect) and later find practical tradeoff solutions to reach towards ideality.

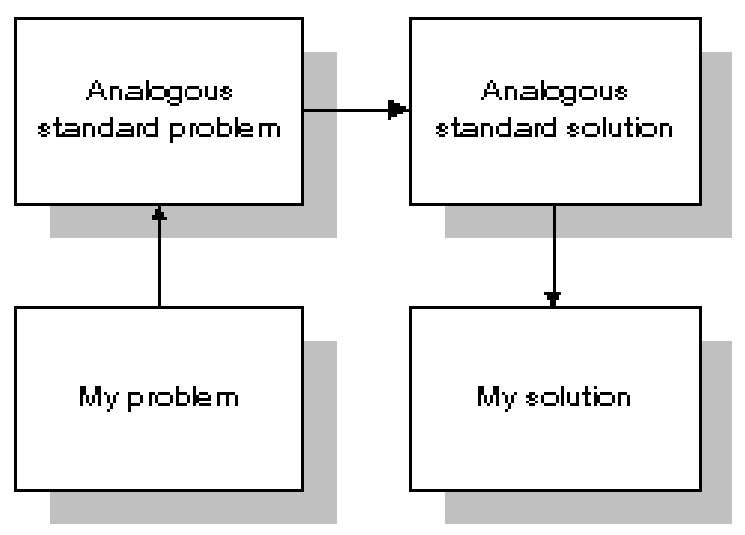

Fig- 1: General problem solving model

\subsection{Abstraction}

Human beings solve problem by analogy. For a particular manner of problem, the solution is sought in a standard set of answers and alternatives.

This led to Altshuller's first classic- "Principle of solution by abstraction" where abstract set of problems are specific problems are collectively categorized into an abstract problem repository. Specific answers are sought from the abstract solutions from the repository.

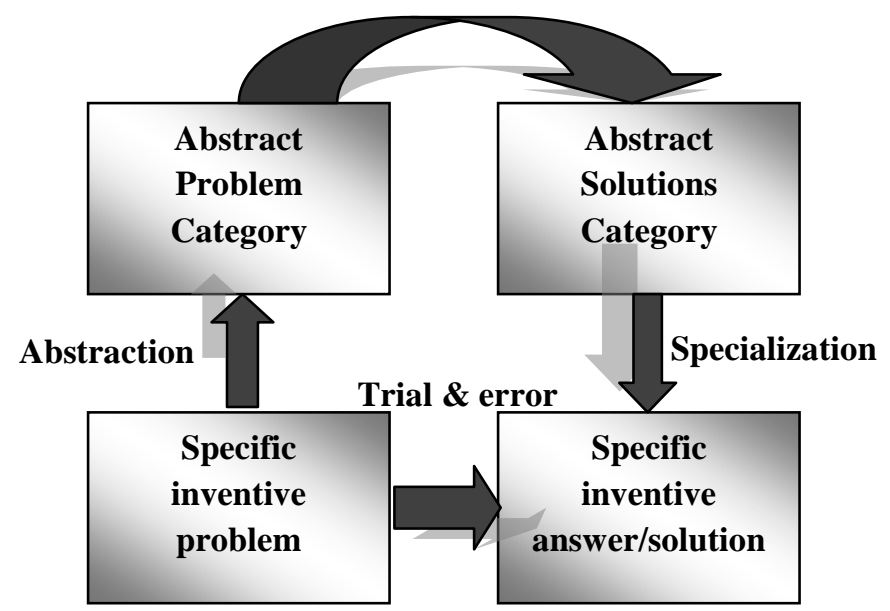

Fig -2: Abstraction Model

\subsection{Contradiction}

Altshuller's second classic- From here Altshuller devised Technical contradiction matrix where for 39 engineering parameters problem there are set of 40 types of standard likely solutions. A technical contradiction arises when two different elements (A \&B) conflict with each other -if one A improves, the other B degrades. E.g. - Increase chair strength increases material thickness but decrease cost effectiveness.

\begin{tabular}{|c|c|c|c|c|c|c|}
\hline & $\begin{array}{l}\text { Worsening } \\
\text { Feature } \\
\text { Improving } \\
\text { Feature }\end{array}$ & 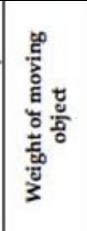 & 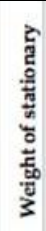 & 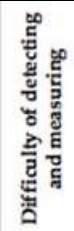 & 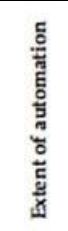 & 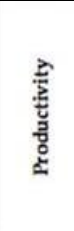 \\
\hline & & 1 & 2 & 37 & 38 & 39 \\
\hline 14 & Strength & $\begin{array}{c}1,8,40 \\
15\end{array}$ & $\begin{array}{r}40, \\
27\end{array}$ & $\begin{array}{l}27,3, \\
15,40\end{array}$ & 15 & $\begin{array}{l}29,35, \\
10,14\end{array}$ \\
\hline 15 & $\begin{array}{c}\text { Duration of action of moving } \\
\text { object }\end{array}$ & $\begin{array}{l}19,5 \\
34,31\end{array}$ & 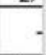 & $\begin{array}{l}19,29, \\
39,35\end{array}$ & 6,10 & $\begin{array}{l}35,17 \\
14,19\end{array}$ \\
\hline 16 & $\begin{array}{l}\text { Duration of action by } \\
\text { stationary object }\end{array}$ & - & $\begin{array}{c}6,: \\
19,\end{array}$ & $\begin{array}{c}25,34 \\
6,35\end{array}$ & 1 & $\begin{array}{l}20,10, \\
16,38\end{array}$ \\
\hline 17 & Temperature & $\begin{array}{r}36,22 \\
6.38 \\
\end{array}$ & $\begin{array}{r}22, \\
3\end{array}$ & $\begin{array}{l}3,27 \\
35,31\end{array}$ & $\begin{array}{l}26,2, \\
19.16\end{array}$ & $\begin{array}{c}15,28 \\
35\end{array}$ \\
\hline
\end{tabular}

Fig -3: Contradiction matrix

In some systems there is only element that affects the system. Here lies Physical Contradiction where elements compete 
itself. E.g. - Chair should be heavy so that it will be stable if a person stands on it; but it should be light to be lifted by mere fingers.

Therefore one should use technical matrix to find abstract solutions for his specific problem and then use physical contradiction to achieve tangible solution. The outcome can be usage of hollow material cross section with corrugation which increases strength, keeps the structure light and can be cost effective too.

\subsection{Substance Field Analysis}

Altshuller's third classic- Substance-Field (Su-field) Analysis is a TRIZ analytical tool for modeling problems related to existing technological systems. Every system is created to perform some functions. The desired function is the output from an object or substance (S1), caused by another object (S2) with the help of some means (types of energy, F). It enables to zoom in on the zone of interest. However, the analysis can be applied to entire system as well as component levels. Such complex models can be simplified by wisdom and knowledge which itself calls for innovation.

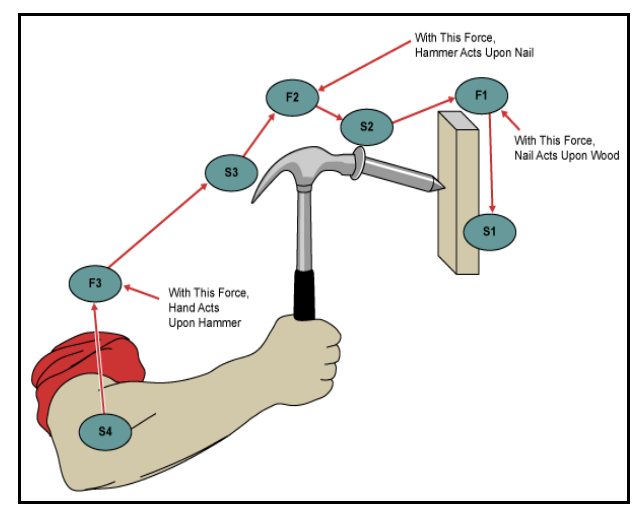

Fig- 4: Example of a system comprising of substances and fields

Besides Altshuller's above work, he also devised theories like eight patterns of technological invention and ARIZ algorithm of problem solving. As time evolved, many researchers worldwide are working on betterment of TRIZ and many theories and models have been devised like Root Conflict Analysis (RCA+) for decomposing inventive problems, Problem Networking for managing complex problems involving networks of contradictions, Hybridization (further development of Alternative Systems Merging), Functional Clues , Anticipatory Failure Determination (AFD),FunctionOriented Search, Inventive Standards for Business Systems, Radar Plot for Mapping Trends of Systems Evolution. The above tools are basically amalgamation of TRIZ knowledge and modern computer software models for TRIZ and are readily available to interest pursuant for purchase.

\section{PROBLEM CONTEXT}

The Author's1 work organization was facing a chronic issue of metal/sand mixture remains (debris/particulate mattermeasured as more than $600 \mathrm{mg}$ against specification of $70 \mathrm{mg}$ ) in the engine block pockets as shown in the image; after machine cleaning just prior to assembly. Such matter is harmful as eventually they would enter the oil galleries of the engine block during engine running and later lead to catastrophe like connecting rod scouring, oil pump failure, crankshaft journal scouring et al.

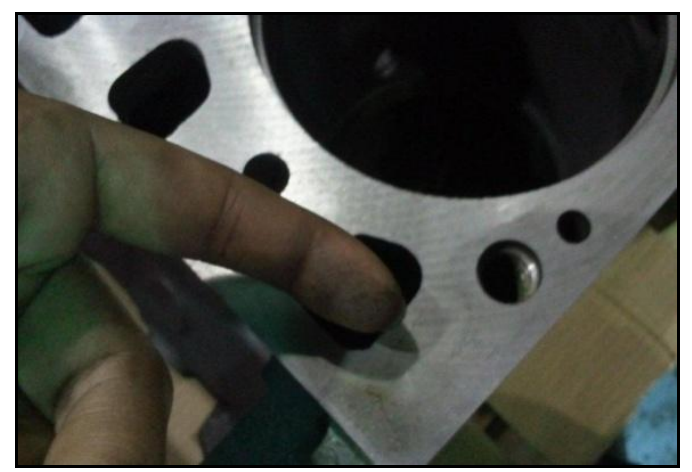

Fig-5: Sand/ metal dust mixture in engine block pockets

\section{TACKLING THE PROBLEM}

The Author's1 one is the last department in the machining chain of the engine blocks, after that assembly of engine is done. So the author being cell leader of the cleaning section is responsible for the quality and timely delivery of the engine blocks supplied for assembly. Perhaps the input quality of engine blocks to the cleaning section is beyond the machine's capablity of his section and therefore the end result is particulate matter/debris found in the engine pockets that could not get cleaned from his machine.

The problem is tackled by a thinner wash and finger scrubbing inside the pockets as shown in the below image i.e. Prework done- manual cleaning of the engine pockets followed by a spray jet machine cleaning. Dust/Particulate matter is stuck at intricate corners locations where machine liquid spray jets don't reach (dust stuck up on anti gravity locations) and therefore needed to be removed manually using bare fingers. The process leads to finger injury to the operator and against good manufacturing practices. 


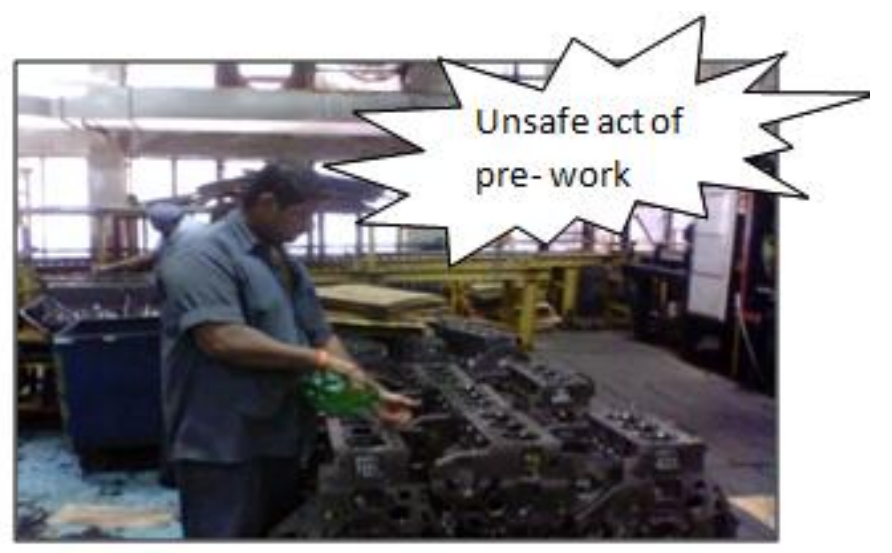

Fig-6: Removal of particulate matter/dust from engine block pockets before final machine block

\section{FINDING SOLUTION THE TRIZ WAY [REF 2]:}

\subsection{Step1}

The initial roadblock to the solution finding process was the Author's1 hesitance of undertaking an improvement project stating that the problem lies in the input quality to his machine. It is not his problem. This psychological inertia was killed by Author's1 project guide 2 who made him realize the power of TRIZ and acquainted him to rise above his individual construct of reality typically folkloric in a manufacturing organization.

\subsection{Step2}

Creation of a halo effect of the problem and taking it towards ideal situation. This step enabled the author to devise new workable solutions to tackle the problem.

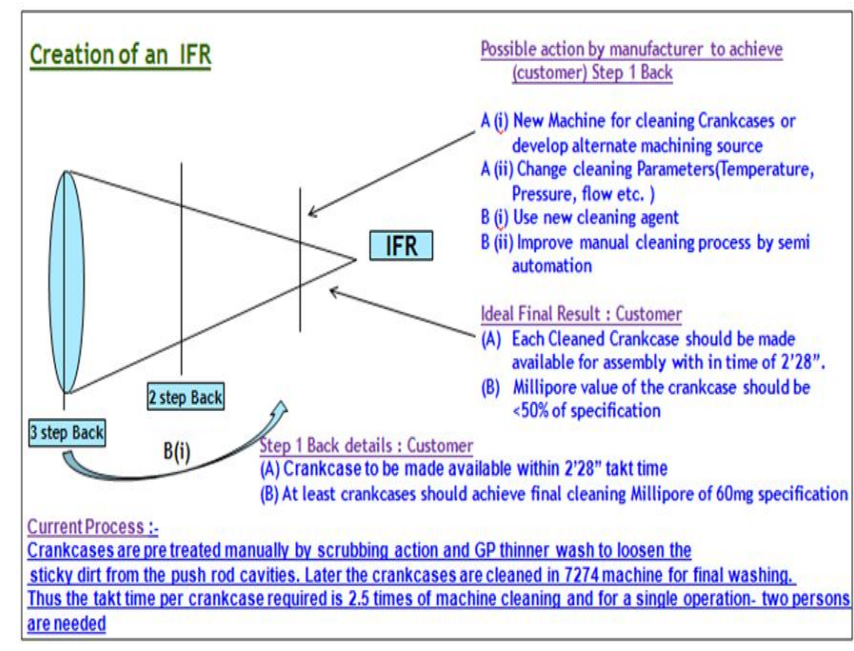

Fig- 7 Ideal final result to eliminate manual cleaning and achieve desired quality after only machine cleaning

\subsection{Step3}

Functional Analysis Diagram- TRIZ Function Analysis is different from other forms in that it includes all the negative, ineffective and excessive interactions in the system, and thus proper understanding of the problems and potential solution points in the system can be determined. The author drew the functional diagram to get a bird's eye view of entire value chain from engine block casting to engine assembly

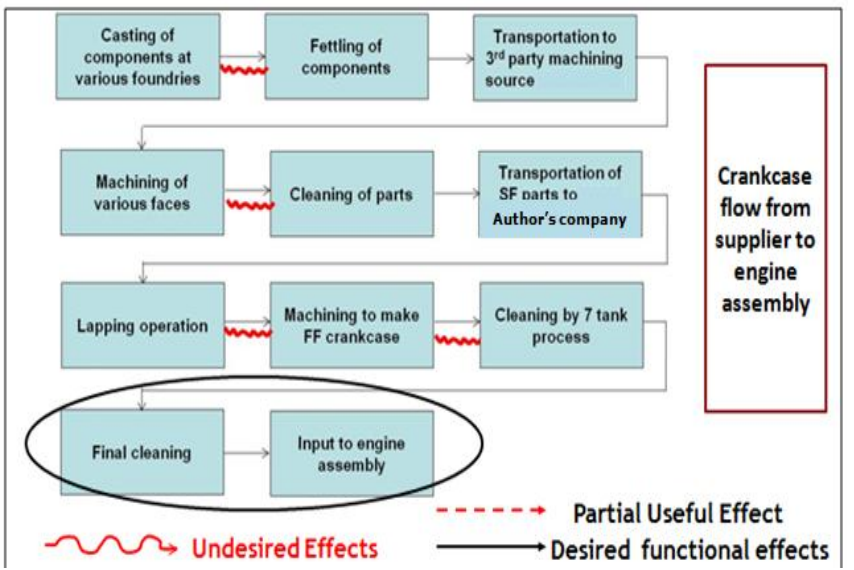

Fig 8 Functional flow diagram- Mapping the entire value chain

\subsection{Step4}

The next step was to work on contradictions so that cleaning can be done in the affected area effectively and with lesser throughput time.

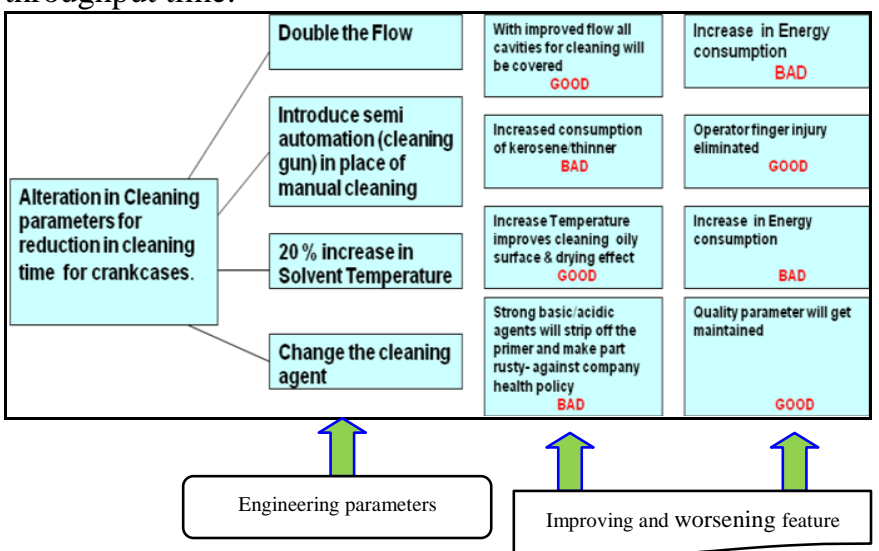

Fig- 9 Finding contradictions

The author then worked on each mechanical parameter and used the Altshuller's contraction matrix as below to find likely abstract solutions (standard 40 solutions) as below- 


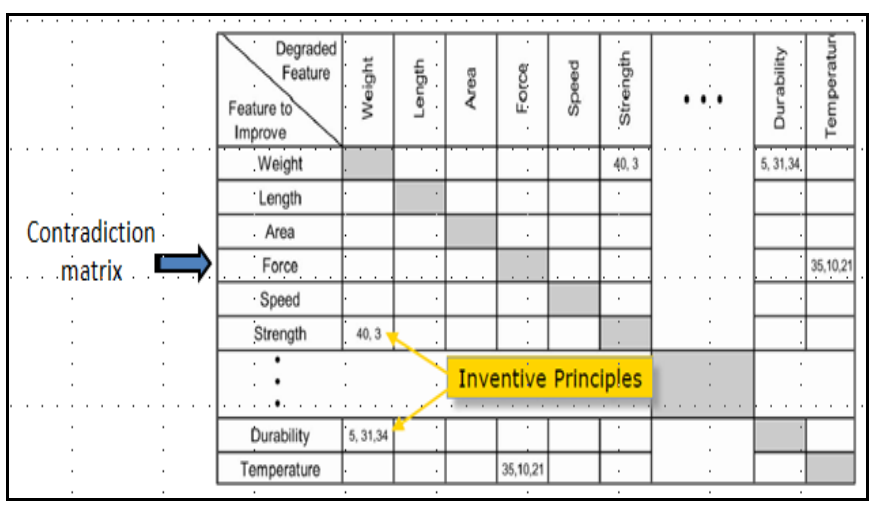

Fig- 10 How to use a contradiction matrix template

Thus the author could derive few workable solutions as indicated in the below table-

\begin{tabular}{|c|l|l|}
\hline \multicolumn{1}{|c|}{ Formulate } & \multicolumn{1}{|c|}{$\begin{array}{c}\text { Identify } \\
\text { Separation Principles }\end{array}$} & \multicolumn{1}{|c|}{ Possible Ideas } \\
\hline \multirow{2}{*}{$\begin{array}{c}\text { (i) Adjustable parameters } \\
\text { Double the flow }\end{array}$} & No. 14. Spheroidality-Curve & $\begin{array}{l}\text { Replace linear surface with curved } \\
\text { flow- Not applicable }\end{array}$ \\
\cline { 2 - 3 } $\begin{array}{l}\text { - Feature to Improve: Stress or } \\
\text { Pressure }\end{array}$ & No.10.Preliminary action & $\begin{array}{l}\text { Do prior action i.e. build pressure- } \\
\text { Not applicable }\end{array}$ \\
\cline { 2 - 3 } - Worsening Feature: Loss of \\
Energy & No.35.Parameter changes & $\begin{array}{l}\text { Changes- Increase in flow of } \\
\text { solvent- Need to provide a } \\
\text { solution like dedicated manifold } \\
\text { for cleaning at particular push rod } \\
\text { area or concentrated flow by } \\
\text { designing nozzles for the same. }\end{array}$ \\
\cline { 2 - 3 } & $\begin{array}{l}\text { Use } \\
\text { resonance/vibration/oscillations- } \\
\text { This would be possible by changing } \\
\text { the program logic of the cleaning } \\
\text { machine and add more vibratory } \\
\text { cycles while cleaning push rod } \\
\text { cavity. }\end{array}$ \\
\hline
\end{tabular}

Fig-11 Identifying separation principles in your own problem

From the above step, the author could understand the need to double the flow of cleaning liquid in the affected pockets and need of resonating pulse of cleaning jet in the affected area. The primary idea is to do only machine cleaning and eliminate manual finger cleaning.

\subsection{Step5- Physical contradiction}

Here the author realized the need of machine nozzle which should be slender enough to enter the push rod cavity like human finger as well as strong/firm enough to withstand 12 bars liquid pressure. Therefore the author introduced new flute type construction machine nozzles in the machine that will clean the affected area and introduced resonating effect in cleaning by modifying the machine PLC logics. The results were encouraging and the particulate matter count (millipore) reduced from $400 \mathrm{mg}$ to $100 \mathrm{mg}$ - however still consistent result of $70 \mathrm{mg}$ as specified in process control chart not achieved yet. The said exercise is level 3 invention in order to improve the current system and isolate the problematic area.

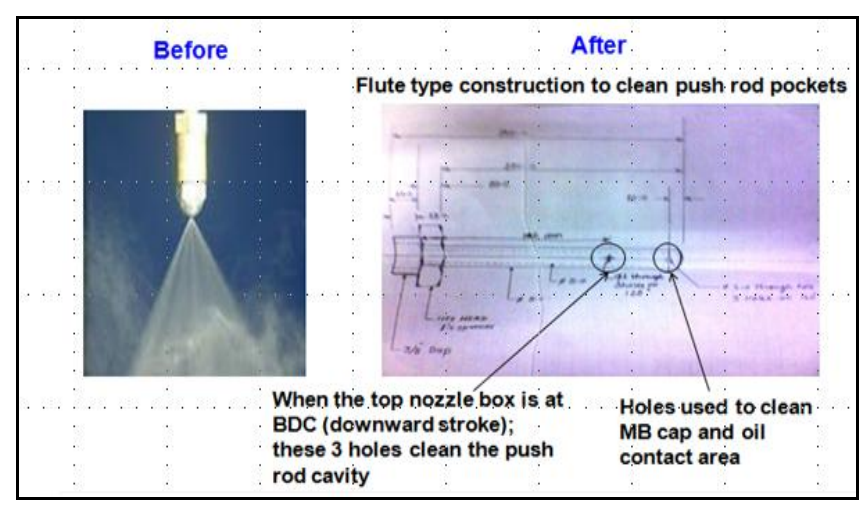

Fig- 12 Innovative nozzle design to clean the engine block pockets- ideation generated from microvascular printing

\subsection{Step6}

Thus the author went ahead with the next level of TRIZ tool and used SU-field analysis so as to solve this problem beyond his paradigm (4th level of invention). He used SU- H diagram (ZZA Algorithm) coined by Zusman and Zlotin to find what really happens during each stage of casting to machine to final cleaning.

Here he realized the rust preventive oil applied by third party machining vendor is the real cause which makes the black sand/dust mixture stay stuck on the internal pockets of the engine.

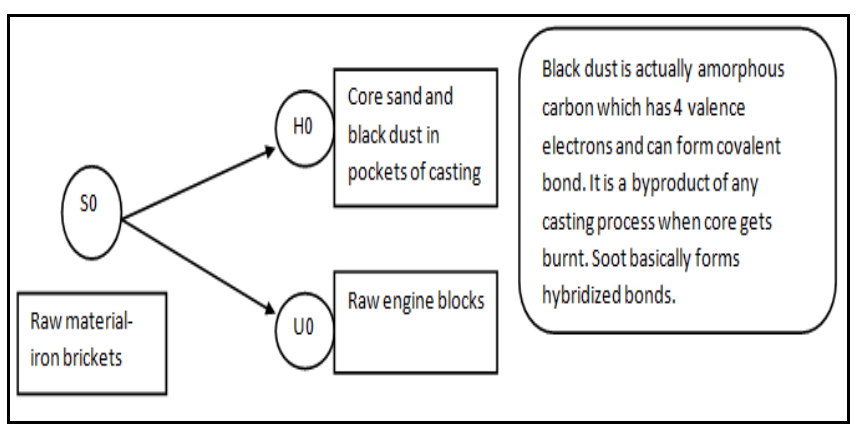

Fig- 13 SU-H Diagram stage1

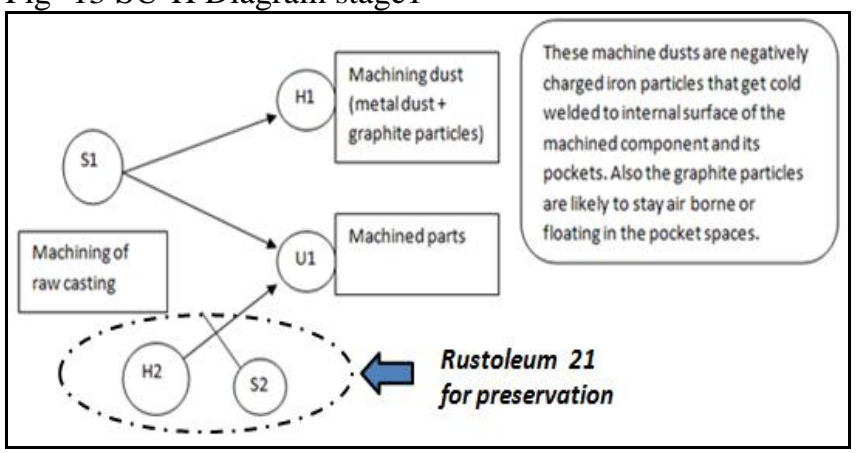

Fig- 14 Level 2 of SU-H diagram 
Therefore finally the author concluded that by mere improving his own machine's capability is not going to solve the problem and some measures needed to be taken at third party machining source too. Therefore he proposed a lighter- less viscous oil for rust prevention at machining supplier end in order to reduce adhesion ability of metal/sand dust inside the pockets.

The below actions have been completed in the project so far-

\begin{tabular}{|c|c|}
\hline$\frac{\text { Actions Taken-TRlz }}{\text { solutions }}$ & Status \\
\hline $\begin{array}{l}\text { 1. Design \& Manufacture of modified } \\
\text { nozzles- } 8 \text { nos: (Localized flow increase } \\
\text { exercise) }\end{array}$ & $\begin{array}{l}\text { Flute type construction cleaning nozzles (8 nos. } \\
\text { for } 8 \text { pockets) for localized cleaning introduced } \\
\text { in the machine. Action Complete }\end{array}$ \\
\hline $\begin{array}{l}\text { 2. Modify the ' machine auto cycle ' for } \\
\text { providing more oscillating motion' to } \\
\text { cleaning jets inside the push rod cavities. }\end{array}$ & $\begin{array}{l}\text { Oscillation cleaning cycle introduced of } 22 \\
\text { seconids introduced in the push rod pockets by } \\
\text { modifying the PLC.logic in the machine- Action } \\
\text { Complete }\end{array}$ \\
\hline $\begin{array}{l}\text { 3. Introduction of lighter preservation oil } \\
\text { from machining supplier on semi-finish } \\
\text { engine blocks before dispatch }\end{array}$ & $\begin{array}{l}\text { Requirement initiated at third party machining } \\
\text { supplier in Jan } 2014 \text { and trial lots expected } \\
\text { sooner-Work in progress }\end{array}$ \\
\hline
\end{tabular}

\section{RESULTS:}

* Tangible-

- Conformance to quality parameter of millipore below $70 \mathrm{mg}$ after machine cleaning of engine blocks, without any manual prework

- Lesser Throughput time as no waiting for the casual labour arrival to do prework

- No use of kerosene/ GP thinner to clean the pockets

* Intangible-

- No finger injury to casual labour

- Adherence to good manufacturing practices

- Learnt TRIZ and happy to do an out of box training

\section{SUMMARY}

By this project, the authors could achieve elimination of unsafe act in his workplace, adherence of product and process as per set standard operating norms. The throughput (productivity) of the cleaning cell (Author's1 work department) has increased by elimination of NVA. Also pragmatically the author could bring the third party machining vendor and his quality department into same platform and all the three parties are equally responsible to achieve quality of the engine blocks which was earlier overlooked by the later two.

\section{CONCLUSIONS}

Looking at adaptive, scientific approaches in manufacturing organizations to experimentation provides improved benefits to the system. The TRIZ tools adopted by the authors to conduct the projects outperform the traditional approaches undertaking a project. The projects mainly hovered around improving Quality of product, process and service; ultimately a step towards reducing "Loss to the Society- coined by Dr. Genichi Taguchi”

The authors have derived immense Joy of leaning from the project and feel TRIZ learning as feather on their Cap $\&$

finally

The author1 wishes to pursue further $\mathrm{PhD}$. Education and TRIZ would be his probable area of interest for the same. Besides, the author 2 would like to enlighten more minds in future by the same subject.

\section{ACKNOWLEDGEMENTS}

It gives me great pleasure and satisfaction to present our technical paper on "APPLICATION OF TRIZ". We would like to thank to our honourable Principal, Dr. P. H. Sawant of 'Sardar Patel College of Engineering' for giving us opportunity to carry out the thesis work on the topics discussed in the paper.

Further we would like to extend our thanks to our coworkers from SPCE for direct or indirect help to prepare and to present this topic. During our project meetings we received a lot of honest criticism; that was instrumental to changing various aspects of our research and we are thankful for this.

We sincerely apologize to and beg the forgiveness of any student, teacher, or author whose work we used for our project but failed to acknowledge.

\section{REFERENCES}

[1]. Kaplan, Stan. "An Introduction to TRIZ: The Russian Theory of Inventive Problem Solving." Draft. Ideation International, Inc. Santa Monica, CA. Fax: +1 (810) 353-5495. [2]. Apte, Prakash R. "Problem solving and Opportunity Creation using TRIZ Innovative Methods", Department of Electrical Engineering, IIT Bombay, Powai, Fax: (0091 22) 25723707

[3]. Tilo Pfeifer, Martin Tillmann "Innovative Process Chain Optimization - Utilizing The Tools Of Triz And Toc For Manufacturing", Fraunhofer Institute for Production Technology, Aachen, Germany, November 2003 


\section{Other Reference Articles-}

[1]. Frank Gornall "TRIZ CASE STUDY- SRES DUCTING", BAE SYSTEMS Design (W16), Warton Aerodrome, Preston, Lancashire PR4 1AX

[2]. Tzu-Chang CHEN "On Patentability of Inventions Facilitated by TRIZ Methodology" Japan TRIZ Symposium 2008 Paper \#44 T.C. Chen (Taiwan)

[3]. Martin Pratt (ME - Research, IMechE) "TRIZ Workshop to redesign an industrial fire-alarm", http://www.imeche.org.uk/manufacturing/triz.asp, Tel: 020 7973 1261, m_pratt@imeche.org.uk

[4]. Kas Kasravi "Applications of TRIZ to IT: Cases and Lessons Learnt" HP fellow, kas.kasravi@hp.com

[5]. Toru Nakagawa "Introduction to TRIZ (Theory of Inventive Problem Solving): A Technological Philosophy for Creative Problem Solving, Toru Nakagawa (Osaka Gakuin University)", The 23rd Annual Symposium of Japan Creativity Society, Held at Toyo University, Tokyo, on November 3-4, 2001 (in Japanese); English transl. by Toru Nakagawa on Dec. 25, 2001 